Final Project Report

\title{
INERT-MATRIX FUEL: ACTINIDE "BURNING" AND DIRECT DISPOSAL
}

\author{
Nuclear Engineering Education Research Program \\ (grant \# DE-FG07-99ID13767)
}

\author{
Rodney C. Ewing (co-PI) \\ Lumin Wang (co-PI)
}

October 30, 2002

For the Period of 07/01/1999 to 06/30/2002

Department of Nuclear Engineering and Radiological Sciences University of Michigan

Ann Arbor, MI 48109 


\section{Background}

Excess actinides result from the dismantlement of nuclear weapons $\left({ }^{239} \mathrm{Pu}\right)$ and the reprocessing of commercial spent nuclear fuel (mainly ${ }^{241} \mathrm{Am},{ }^{244} \mathrm{Cm}$ and ${ }^{237} \mathrm{~Np}$ ). In Europe, Canada and Japan studies have determined much improved efficiencies for burnup of actinides using inert-matrix fuels. This innovative approach also considers the properties of the inert-matrix fuel as a nuclear waste form for direct disposal after onecycle of burn-up. Direct disposal can considerably reduce cost, processing requirements, and radiation exposure to workers.

\section{Objectives}

The objectives of this NEER program are to study the nuclear fuel and waste form properties of the most promising inert-matrix fuels (i.e., cubic zirconia and spinelzirconia composites). The main topics of study as listed in the original proposal are: a) the effect of fission event (in-reactor) and alpha-decay event (in-repository) damage on the physical and chemical properties that are important to nuclear fuel (e.g., bubble formation and swelling) and nuclear waste forms (e.g., leach rate and micro-fracturing) performance; b) The solubility and the mobility of the fission and other important transmutation products in the inert fuel matrix at both high (reactor fuel condition) and low (waste form condition) temperatures. We have also stated in the original proposal that this research program would be conducted with international collaborations.

\section{Research Accomplishments}

During the past three years, we have made a significant accomplishment on the research program. We have completed a systematic study of some major effects on the yattria stabilized zirconia (YSZ) microstructure due to fission product incorporation and associated radiation damage. In addition, we have studied the effects of fission product incorporation and radiation on the microstructure of YSZ/spinel composite material. These results are valuable in the development and evaluation of the zirconia based inert matrix fuels. Our study supported by this NEER program has resulted in 14 scientific research papers (see 3.2) and 17 presentations at national or international conferences 
(see 3.3), including the Material Research Society (MRS) annual meeting, American Nuclear Society (ANS) annual meeting, Microscopy Society of America (MSA) and Microbeam Analysis Society (MAS) joint annual meeting, International Conference on Inert matrix Fuel and International Conference on Ion Beam Modification of Materials.

The graduate student supported by this NEER program, Sha Zhu, has won two major national awards at the MSA/MAS joint meeting in 2001 (Long Beach, CA): MAS Distinguished Scholar Award and the MSA Second Best Poster Award for Physical Science Applications of Microscopy. We have collaborated with researchers at Argonne National Laboratory (R.C. Birtcher), Pacific Northwest National Laboratory (W.J. Weber) and European Commission Joint Research Center in Karlsruhe, Germany $(\mathrm{Hj}$. Matzke). The graduate student supported under this NEER program has been trained to use the IVEM-Tandem Facility at Argonne National Laboratory to conduct in situ TEM studies on radiation effects in materials during ion beam bombardment.

\subsection{Awards}

The student supported under this NEER program, Sha Zhu has won two major awards at the MSA/MAS joint meeting (Long Beach, CA, August 2001):

1. Microbeam Analysis Society (MAS) Distinguished Scholar Award;

2. Microscopy Society of America (MSA) Second Best Poster Award for Physical Science Applications of Microscopy.

\subsection{Publications}

1. L.M. Wang, S.X. Wang and R.C. Ewing, Amorphization of cubic zirconia by cesium ion implantation, Philosophical Magazine Letters 80 (2000) 341-347.

2. A. Meldrum, L.A. Boatner and R.C. Ewing, Nanocrystalline zirconia can be amorphized by ion irradiation, Physical Review Letters 88(2) (2000) 025503-1-4.

3. N.P. Laverov, S.V. Yudintsev, S.V. Stefanovsky, J. Lian and R.C. Ewing, Radiation stability of actinide matrices (in Russian), Doklady of the Russian Academy of Sciences, vol. 376, no. 5., 665-667 Or Transactions of the Russian Academy of Sciences, Earth Science Section (2001) vol. 377, pt. 2, 175-177 (in English).

4. L.M. Wang, S.X. Wang, S. Zhu and R.C. Ewing, Effects of fission product incorporation on the microstructure of cubic zirconia, Journal of Nuclear Materials (2001) 289, 122-127.

5. L.M. Wang, S. Zhu, S.X. Wang, R.C. Ewing, N. Boucharat, A. Fernandez , H. Matzke (2001) Effects of xenon implantation in spinel-zirconia/ceria composites, Progress in Nuclear Energy 38 (2001) 295-300. 
6. L.M. Wang, S. Zhu, S.X. Wang and R.C. Ewing, Effects of cesium, iodine and strontium ion implantation on the microstructure of cubic zirconia, Materials Research Society Symposia Proceedings 663 (2001) 293-300.

7. Sha Zhu, Lumin Wang, Shixin Wang and Rodney C. Ewing, Effect of iodine and strontium ion implantation on the microstructure of cubic zirconia, Materials Research Society Symposia Proceedings 647 (2001) O11.19.1-6.

8. S. Zhu, L.M. Wang, S.X. Wang, J. Lian and R.C. Ewing, TEM study of nano-crystals in strontium ion-implanted cubic zirconia, Microscopy and Microanalysis 7, Supplement 2 (Proceedings of Microscopy and Microanalysis 2001, Long Beach, CA, August 5-9, 2001, Springer), pp. 406-407.

9. L.M. Wang, S. Zhu, R.C. Ewing, Behavior of fission products in YSZ-based inert matrix fuel, Transactions of the American Nuclear Society 84 (Proceedings of the 2001 Annual Meeting of American Nuclear Society, June 17-21, 2001, Milwaukee, WI, June 17-21, 2001, Milwaukee, WI), pp. 103-104.

10. S. Zhu, X.T. Zu, L.M. Wang and R.C. Ewing, Nanodomains of pyrochlore formed by Ti ion implantation in yttria-stabilized zirconia, Applied Physics Letters 80 (2002) 4327-4329.

11. S. Zhu, X.T. Zu, L.M. Wang and R.C. Ewing, Cesium ion implantation in single crystal yttria-stabilized zirconia (YSZ) and polycrystalline $\mathrm{MgAl}_{2} \mathrm{O}_{4}-\mathrm{YSZ}$, Materials Research Society Symposia Proceedings 713 (2002) JJ11.11.1-6.

12. S. Zhu, X.T. Zu and L.M. Wang, TEM study of formation of nano-domains of pyrochlore in titanium ion implanted yttria stabilized zirconia, Proceedings of the 15th International Congress on Electron Microscopy (Durban, South Africa, September 1-6, 2002), Vol. 1. Physics and Materials, pp. 399-400.

13. S. Zhu, X.T. Zu, X. Xiang, Z.G. Wang, L.M. Wang and R.C. Ewing, Electron microscopy and optical spectroscopy study of xenon-implanted yttria-stabilized zirconia, Nuclear Instrument and Methods B, in press.

14. S. Zhu, S. X. Wang, X.T. Zu, L.M. Wang, R.C. Ewing and R.C. Birtcher, TEM study of nano-precipitates of $\mathrm{SrZrO}_{3}$ in yttria stablized zirconia by ion implantation and thermal annealing, Applied Physics Letters, submitted.

\subsection{Presentations}

1. L.M. Wang, S.X. Wang and R.C. Ewing, Radiation effects in cesium ion implanted zirconolite and zirconia. Presented by R.C. Ewing at the International Global'99 Conference (August 29 to September 3, 1999, Jackson Hole, Wyoming).

2. L.M. Wang, S.X. Wang and R.C. Ewing, Effects of Cesium Ion Implantation in Yttria Stabilized Cubic Zirconia. Presented at the 5th International Inert Matrix Fuel Workshop (Paris, France, October 22, 1999).

3. L.M. Wang, S.X. Wang, S. Zhu, R.C. Ewing, Effects of fission product incorporation on the microstructure of cubic zirconia. Presented at the 102th Annual Meeting of the American Ceramic Society (April 30-May 2, 2000, St. Louis, MO).

4. L.M. Wang, S. Zhu, S.X. Wang, R. C. Ewing, N. Boucharat, A. Fernandez and Hj. Matzke, Effects of xenon ion implantation in spinel-ceria and spinel-cubic zirconia 
composites. Presented by R.C. Ewing at the 6th International Inert Matrix Fuel Workshop, European Material Research Society 2000 Spring Meeting (May 30 June 2, 2000, Strasbourg, France).

5. L.M. Wang, S.X. Wang, S. Zhu, R.C. Ewing, Effects of fission product accumulation in cubic zirconia. Presentated at the Topical Conference on Plutonium Futures - The Science (July 10-13, 2000, Santa Fe, New Mexico).

6. R.C. Ewing, L.M. Wang, S.X. Wang and S. Zhu, Fission product incorporation in cubic zirconia as inert matrix fuel. Presented at the $24^{\text {th }}$ International Symposium on the Scientific Basis for Nuclear Waste Management (August 27-31, 2000, Sydney, Australia).

7. L.M. Wang, S. Zhu, S.X. Wang and R.C. Ewing, Formation of nanocrystals in strontium ion implanted cubic zirconia. Presented at the International Conference on Ion Beam Modification of Materials 2000 (September 3-8, 2000, Rio Grande do Sul, Brazil).

8. L.M. Wang, Radiation effects in nuclear waste materials and their consequences. Presented at the TMS (The Minerals, Metals and Materials Society) 2000 Fall Meeting, St. Louis, MO, (October 9, 2000, Invited Talk).

9. Sha Zhu, Lumin Wang, Shixin Wang and Rodney C. Ewing, Effect of iodine and strontium ion implantation on the microstructure of cubic zirconia, Presented at the Materials Research Society 2000 Fall Meeting, Boston, MA (November 27-december 1,2000 ).

10. L.M. Wang and R.C. Ewing, Nuclear waste forms for the future. Presented at the 221 st National Meeting of the American Chemical Society, San Diego, CA (April 15, 2001, Invited Talk).

11. L.M. Wang, S. Zhu and R.C. Ewing, Behavior of fission products in YSZ-based inert matrix fuel. Presented at the 2001 American Nuclear Society Annual Meeting, Milwaukee, WI (June 20, 2001, Invited Talk).

12. S. Zhu, L.M. Wang, S.X. Wang, J. Lian and R.C. Ewing, TEM study of nano-crystals in strontium ion-implanted cubic zirconia. Presented at the Microscopy \& Microanalysis 2001 Conference, Long Beach, CA (August 5-9, 2001).

13. S. Zhu, X.T. Zu, L.M. Wang and R.C. Ewing, Cesium ion implantation in single crystal yttria-stabilized zirconia (YSZ) and polycrystalline $\mathrm{MgAl}_{2} \mathrm{O}_{4}-\mathrm{YSZ}$. Presented at the Materials Research Society 2001 Fall Meeting, Boston, MA (November 26-30, 2001).

14. L.M. Wang, In situ TEM study of radiation effects in nuclear ceramics": International Conference on Modern Materials and Technologies, the $10^{\text {th }}$ International Ceramic Congress and the $3^{\text {rd }}$ Forum on New Materials, Florence, Italy (July 17, 2002, Invited Talk).

15. S. Zhu, X.T. Zu, L.M. Wang and R.C. Ewing, Electron Microscopy and optical study of xenon-implanted yttria-stabilized zirconia. Presented at the $13^{\text {th }}$ International Conference on Ion Beam Modification of Materials, Kobe, Japan (September 1-5, 2002) 
16. L.M. Wang, TEM study of formation of nano-domains of pyrochlore in titanium ion implanted yittra stabilized zirconia. Presented at the 15th International Congress on Electron Microscopy, Durban, South Africa (September 1-6, 2002).

17. L.M. Wang, S. Zhu and R.C. Ewing, Effects of temperature on the behavior of fission products in ysz-based inert matrix fuel and waste form. Presented at 8th International Meeting on Inert Matrix Fuel, Tokai, Ibaraki, Japan (October 16-18, 2002).

\section{Main Results}

\subsection{Effects of radiation and Cs, I and Sr incorporation in YSZ}

Cesium, iodine and strontium ions have been implanted into yttria-stabilized cubic zirconia (YSZ) to determine the effects of fission product incorporation in YSZ that is considered as an inert nuclear fuel matrix. The ion implantation was conducted at room temperature to $1 \times 10^{21}$ ions $/ \mathrm{m}^{2}$ for each ion with ion energies ranging from 70 to $400 \mathrm{keV}$. The peak displacement damage level and the peak ion concentration in YSZ reached 205$330 \mathrm{dpa}$ and 11-26 at.\%, respectively. The microstructure of the implanted YSZ was studied by in situ and cross-sectional transmission electron microscopy. In the iodine and strontium implanted samples, a damaged layer with a high density of defect clusters was observed, while in the cesium implanted specimen, most damaged layer is amorphous. Nanocrystalline precipitates were observed in the strontium implanted specimen after annealing at $1000^{\circ} \mathrm{C}$. The results have been discussed in terms of the ionic size, mobility and the solubility of the implanted species in YSZ.

In situ TEM during the $70 \mathrm{keV} \mathrm{Cs}{ }^{+}$implantation revealed a high density of defect clusters on the nanometer scale after $\sim 2 \times 10^{20} \mathrm{Cs} / \mathrm{m}^{2}$. The defect clusters with characteristics of interstitial type dislocation loops are interpreted to be the result of planar precipitates of $\mathrm{Zr}$ and/or $\mathrm{O}$ interstitials displaced from their original lattice site by the collisional events. The formation of dislocation loops indicates a high defect mobility in YSZ at the room temperature, and this is consistent with previous results of radiation studies that did not result in amorphization even at a dose of 680 dpa However, amorphous domains in the thin regions of the specimen were observed after $1 \times 10^{21} \mathrm{Cs} / \mathrm{m}^{2}$ with ex situ high resolution TEM (HRTEM) and nanobeam electron diffraction in areas with a Cs concentration of 11 at. \%, as measured by energy dispersive $\mathrm{x}$-ray spectroscopy (EDS). Because the $70 \mathrm{keV}$ implanted Cs ions were only present in a thin layer of $\sim 30$ $\mathrm{nm}$ at the surface and the ion distribution is depth dependent, only the average Cs concentration through the entire thickness can be obtained from the plan-view TEM sample. Cross-sectional TEM of the $400 \mathrm{keV}$ Cs-implanted specimen (Fig.1) confirmed the formation of an amorphous layer that is approximately centered at the depth of peak Cs-concentration, rather than the peak-damage depth. The nature of the amorphous layer was confirmed by both high resolution TEM and convergent beam electron diffraction (Fig. 2). The top and lower boundaries of the amorphous band correspond to a Csconcentration of $\sim 8$ at. \%. Strain contrast in the TEM image at the top of the amorphous layer indicates the formation of a high density of defect clusters and local lattice distortion. 
The results of the $200 \mathrm{keV} \mathrm{I}+$ implantation on the microstruture of YSZ are shown by the bright- and darkfield TEM images in figure 4. A band ( $\sim 50 \mathrm{~nm}$ wide) of defect clusters was apparent towards the end of the calculated ion and damage range, but no amorphization was observed throughout the thickness even at depths with $\sim 26$ at. $\%$ I or $\sim 200$ dpa. Although a more detailed study of the damaged band revealed some morié fringes which may be indications of the formation of precipitate phases, the selected area electron diffraction pattern from the damage band showed that the area is still a single crystal (insert of Fig. 4a). The defect clusters

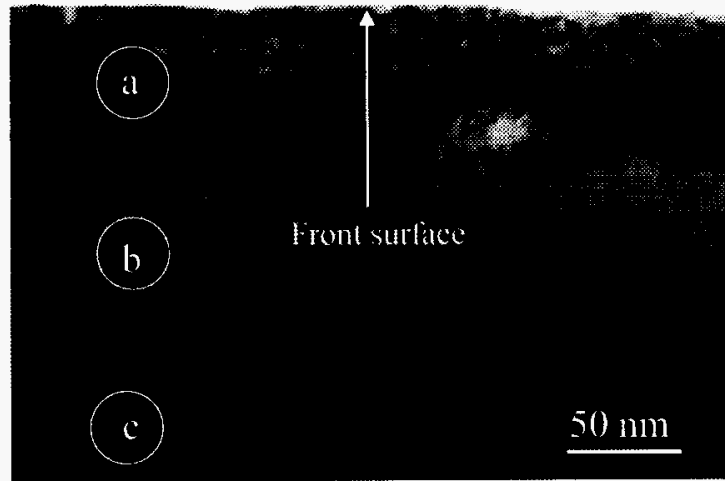

Fig. 1 Bright-field cross-sectional TEM micrograph showing the depth dependent microstructure of YSZ after $400 \mathrm{keV}$ Cs implantation to $1 \times 10^{21}$ ions $/ \mathrm{m}^{2}$ at room temperture. may include dislocation loops (two dimensional point defect clusters), as well as small three dimensional precipitates of interstitials. Because of the high concentration of implanted iodine in the region, most of these defect clusters probably contain iodine.

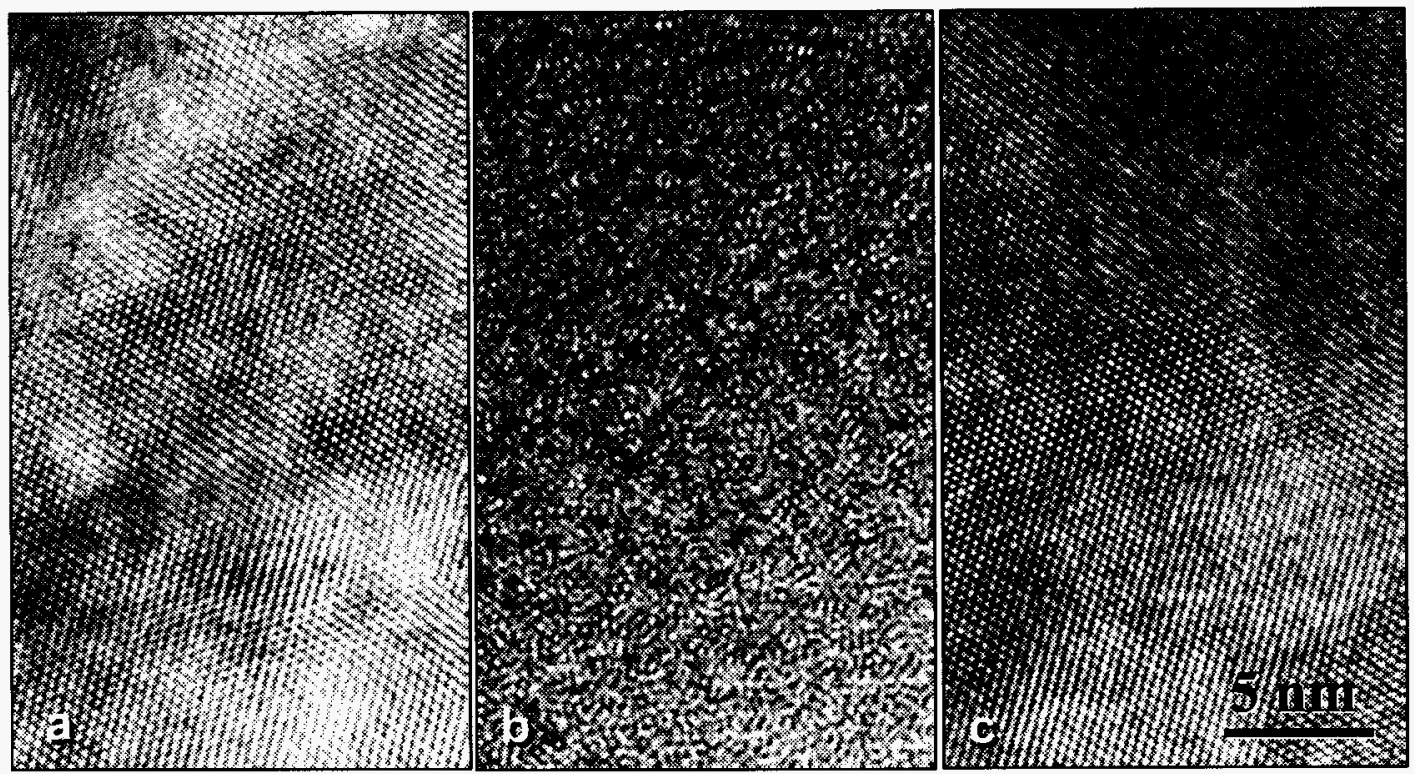

Fig. 2. High resolution TEM micrographs with corresponding convergent electron diffraction patters from the areas marked as (a), (b) and (c), respectively.

In situ $\mathrm{TEM}$ during the $200 \mathrm{keV} \mathrm{Sr}{ }^{+}$implantation also revealed a high density of defect clusters on the nanometer scale after $\sim 2 \times 10^{20}$ ions $/ \mathrm{m}^{2}$, but no evidence of amorphization or secondary phase precipitation after $1 \times 10^{21}$ ions $/ \mathrm{m}^{2}$. The results were confirmed by 
cross-sectional TEM after $400 \mathrm{keV} \mathrm{Sr}^{+}$implantation to $1 \times 10^{21}$ ions $/ \mathrm{m}^{2}$ as shown in a dark-field image $(\mathrm{g}=220)$ of figure 3 . The defect clusters appear to be dislocation loops with diameters ranging from $3-20 \mathrm{~nm}$. The depth of the damage distribution is $50 \mathrm{~nm}$ deeper than the calculated damage range and occurs closer to the implanted ion concentration maximum, rather than the displacement damage maximum, which may be due to the high interstitial concentration at the peak ion concentration. Annealing of the Sr-

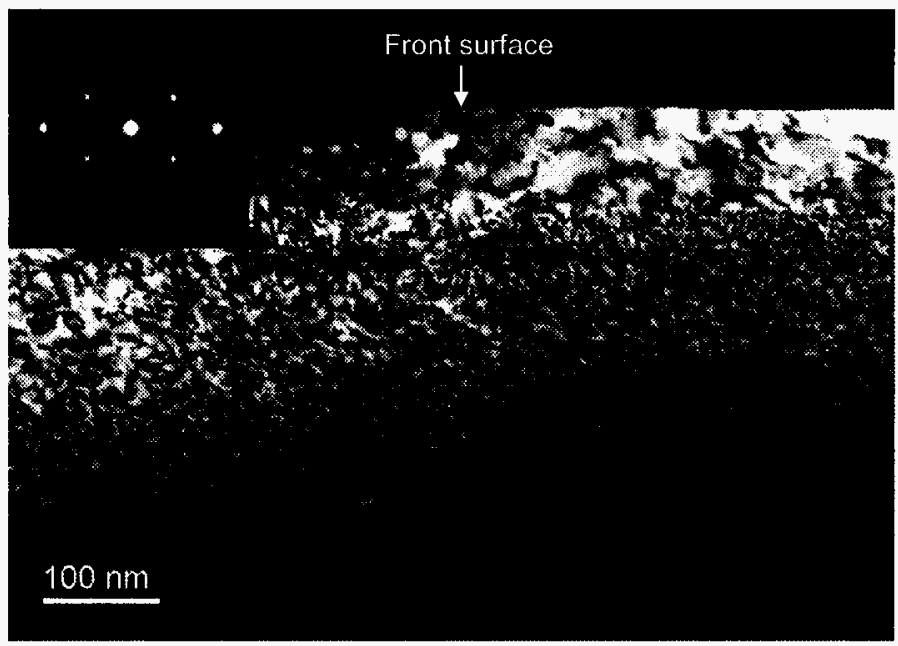

Fig. 3 Dark-field cross-sectional TEM micrograph ( $\mathrm{g}=220$ ) and selected area electron diffraction pattern of a YSZ single crystal after $400 \mathrm{keV} \mathrm{Sr}{ }^{+}$implantation to $1 \times 10^{21}$ ions $/ \mathrm{m}^{2}$ at room temperature showing the depth dependent damage structure implanted sample at $1000^{\circ} \mathrm{C}$ for two hours did not remove the dislocation loops from the damaged microstructure, as shown in a $\mathrm{g}=220$ dark field TEM micrograph (Fig. 4a). However, when the strain field of dislocation loops were tilted out of contrast, small precipitates and cavities were observed in the damaged band (Fig. 4b). The precipitates have dimensions ranging from 5 to $25 \mathrm{~nm}$, and the cavities are of much smaller size $(\sim 3 \mathrm{~nm}$ in diameter) but with a much higher density (Fig. 4b insert). The depth at which the precipitates form corresponds to the depth of the maximum concentration of implanted $\mathrm{Sr}$, and the precipitates have been identified to be $\mathrm{SrZrO}_{3}$ (perovskite structure).

Previous irradiation studies have demonstrated that cubic zirconia is one of the most radiation-resistant of ceramics. Naguib and Kelly have classified zirconia as an oxide that is among the most resistant to irradiation-induced amorphization based on its high bonding ionicity. Swelling in cubic zirconia, without excess gas implantation during neutron irradiations, is minimal although prismatic dislocation loops can be easily generated. Stabilized cubic zirconia can also be destabilized to the monoclinic structure under ionizing irradiation. Recently, irradiations to doses as high as 680 displacement per atoms (dpa), at temperatures as low as $20 \mathrm{~K}$, with an implanted xenon concentration as high as 37 at. \% have failed to amorphize cubic zirconia. The observation of dislocation loops at cryogenic temperatures and the readily formed xenon bubbles confirm the high mobility of point defects and implanted xenon atoms in zirconia. This high mobility promotes the defect recombination and precipitation, and this prevents the build-up of defects or impurity concentrations required for solid-state amorphization. The recently reported radiation-induced polygonization of cubic zirconia at $120 \mathrm{~K}$ is consistent with the structure's strong tendency to crystallize as polygonization is a result of the competition between radiation-induced amorphization and radiation-enhanced 

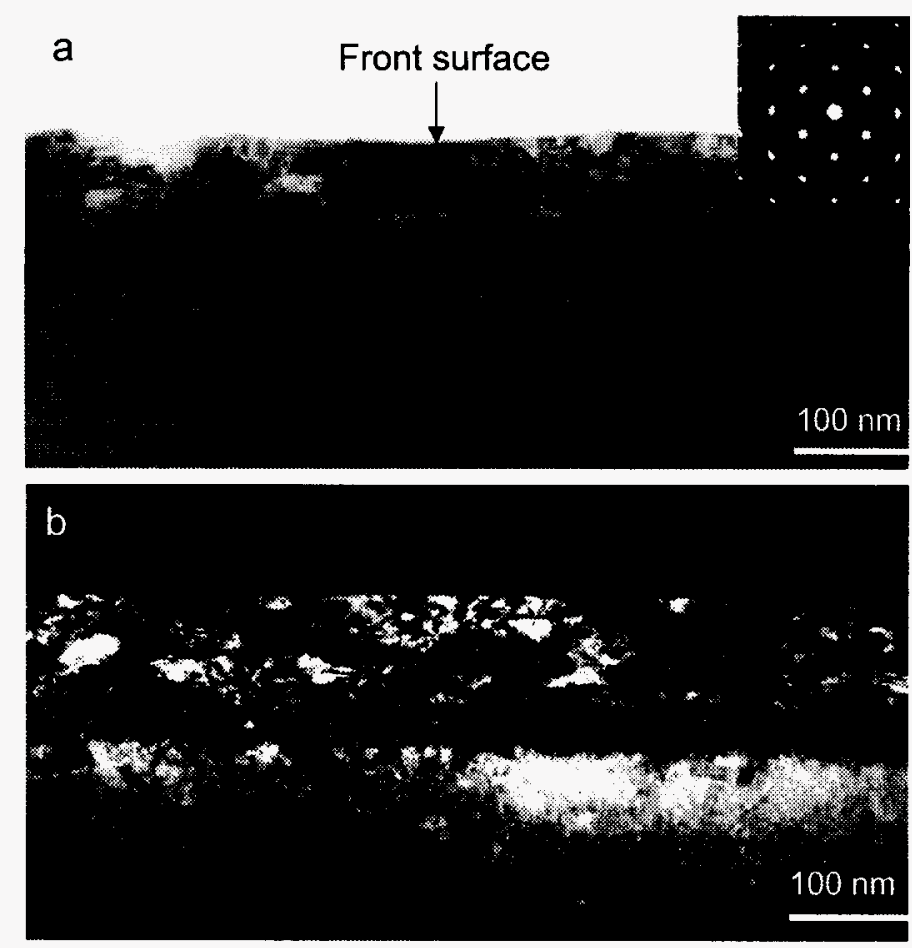

Fig. 4 Bright-field (a) and dark field (b) cross-sectional TEM images of a YSZ single crystal after a $200 \mathrm{keV} \mathrm{I}$ implantation to $1 \times 10^{21}$ ion $/ \mathrm{m}^{2}$. The selected area electron diffraction pattern in (a) shows that the damaged layer remained a single crystal. crystallization that is usually observed just above the critical amorphization temperature. Our observation of radiationinduced dislocation loops in the ion-implanted YSZ is consistent with previous observations.

Although cubic zirconia is known to have high solubility for actinides, there are only limited data on the solubility and mobility of $\mathrm{Cs}, \mathrm{I}$ and $\mathrm{Sr}$ in cubic zirconia. Pouchon et al. recently estimated by thermodynamic calculations that the solubility of $\mathrm{Cs}_{2} \mathrm{ZrO}_{3}$ (at $1000 \mathrm{~K}$ ) and $\mathrm{Cs}$ (at $2000 \mathrm{~K}$ ) in $\mathrm{ZrO}_{2}$ may only be 1.5 at. $\%$, although the highly defective zirconia structure may incorporate higher concentrations of impurities because the impurities may be trapped at

the boundaries of crystal defects. The relatively low solubility of Cs in cubic zirconia suggests that $\mathrm{Cs}$ tends to precipitate in the secondary phases. The precipitation of a secondary phase is prevented by the extremely low Cs-mobility in cubic zirconia at temperatures below $873 \mathrm{~K}$. Apparently, the amorphization of YSZ implanted with excess $\mathrm{Cs}$ is related to the low solubility and mobility of Cs in YSZ.

An important parameter in determining the effect of the implanted species on the threshold amorphization dose is the relative atomic size. The atomic size ratio in crystalline materials has been used to estimate phase stability. As an example, the atomic size ratio $\left(R_{A} / R_{B}\right)$ determines the occurrence of hydrogen-induced amorphization in the $\mathrm{AB}_{2}$-type cubic Laves phase system, for which compounds with a ratio $>1.37$ are amorphized by hydrogenation.

Cubic zirconia has the fluorite structure in which zirconium is 8-coordinated by oxygen and oxygen is 4-coordinated by zirconium. To maintain the fluorite structure, the radius ratio of cation to anion should typically be in the range of 0.732 to 1 . In pure zirconia, the ratio is 0.79 (radius of $\mathrm{Zr}^{4+}=0.098 \mathrm{~nm}$ in 8 -fold coordination). $\mathrm{Zr}^{4+}$ may be substituted by larger cations. However, the maximum cation radius is $0.124 \mathrm{~nm}$ which is approximately that of $\mathrm{O}^{2-} . \mathrm{Cs}^{+}$is a large cation with an effective ionic or crystal radius 
ranging from 0.174 or 0.188 (8-coordinated) to 0.188 or $0.202 \mathrm{~nm}$ (12-coordinated). In comparison, the effective ionic radii of $\mathrm{Sr}$ and I (as cations) have ranges up to 0.140 and $0.109 \mathrm{~nm}$, respectively, and the effective ionic and crystal radii of xenon ranges from 0.04-0.062 $\mathrm{nm}$. Thus, $\mathrm{Cs}^{+}$is incompatible in the cubic zirconia structure. The incorporation of $\mathrm{Cs}^{+}$or cations with ionic radii larger than $0.124 \mathrm{~nm}$ disrupts the local topology in cubic zirconia which leads to amorphization of the structure at high ion fluences. The monovalent charge of $\mathrm{Cs}^{+}$is also incompatible with the fluorite structure. $\mathrm{Cs}^{+}$may try to react with $\mathrm{O}_{2}^{-}$to form $\mathrm{Cs}_{2} \mathrm{O}$ which has the inverse fluorite structure (i.e., with $\mathrm{Cs}$ ions occupying the 4-coordinated anion positions and $\mathrm{O}$ occupying the 8coordinated cation positions in YSZ). For such a reaction, large amount of local atomic rearrangement has to be made.

The ionic radii of $\mathrm{I}^{-}$is large $(0.22 \mathrm{~nm})$, however, it is unlikely that implanted $\mathrm{I}^{+}$will be present in the zirconia as an anion. As cations, iodine radii are much smaller than that of Cs. According to the measurement of $\mathrm{I}^{+}$implanted YSZ by Rutherford Backscattering

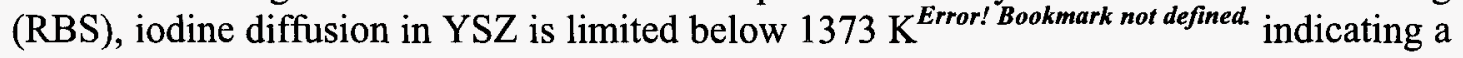
high iodine retention capacity and a rather low iodine mobility in YSZ at lower temperatures. Although the formation of Sr-containing precipitates in the Sr-implanted specimen after annealing suggested a relatively low Sr-solubility and mobility at the room temperature in the YSZ matrix, excess Sr (because of the relatively small ionic size) did not cause amorphization of YSZ.

Because the operating temperature of an inert matrix-fuel in nuclear reactors will be quite high (ranging from $>1600 \mathrm{~K}$ at the core to $873 \mathrm{~K}$ at the rim), Cs-migration, release and precipitation are expected. It is unlikely that the Cs-concentration will be greater than 8 at. $\%$ in the fuel. Thus, zirconia used as an inert matrix fuel will not become amorphous due to in-reactor irradiation. Actually, our later study has indicated that Cs would migrate in YSZ to form bubbles in YSZ at elevated temperatures. Nevertheless, our results show that if excess Cs is generated and retained in the YSZ structure at lower temperatures, radiation-induced amorphization can occur. Amorphization can cause a significant volume swelling and increase in the leach rate of a nuclear waste form.

\subsection{Formation of pyrochlore nanodomains in Ti implanted YSZ}

The microstructural evolution of a single crystal of yttria-stabilized zirconia (YSZ) implanted with $\mathrm{Ti}$ has been studied by cross-sectional transmission electron microscopy (TEM). The implantation of $180 \mathrm{keV}$ Ti ions to a dose of $1 \times 10^{17} \mathrm{ions} / \mathrm{cm}^{2}$ was completed at room temperature. After annealing at $1100^{\circ} \mathrm{C}$ in an Ar atmosphere for 2 hours, a phase transition from the fluorite structure of $\mathrm{ZrO}_{2}$ to an isometric pyrochlore structure-type, $\mathrm{A}_{2} \mathrm{~B}_{2} \mathrm{O}_{7}$, occurred due to cation ordering. High-resolution TEM (HRTEM) revealed

nanodomains of pyrochlore, $\mathrm{Y}_{2}\left(\mathrm{Ti}_{\mathrm{x}} \mathrm{Zr}_{1-\mathrm{x}}\right)_{2} \mathrm{O}_{7}$, with $a \cong 10.24 \pm 0.05 \AA$. The nanodomains of the pyrochlore phase, embedded within the YSZ fluorite substrate, occurred in a depth range from 45 to $105 \mathrm{~nm}$ below the surface, which corresponds to Ti-concentrations from $\sim 10$ to $\sim 15$ at. \% (Fig. 5). The nanoscale pyrochlore precipitates and the YSZ matrix have a completely coherent orientation. 


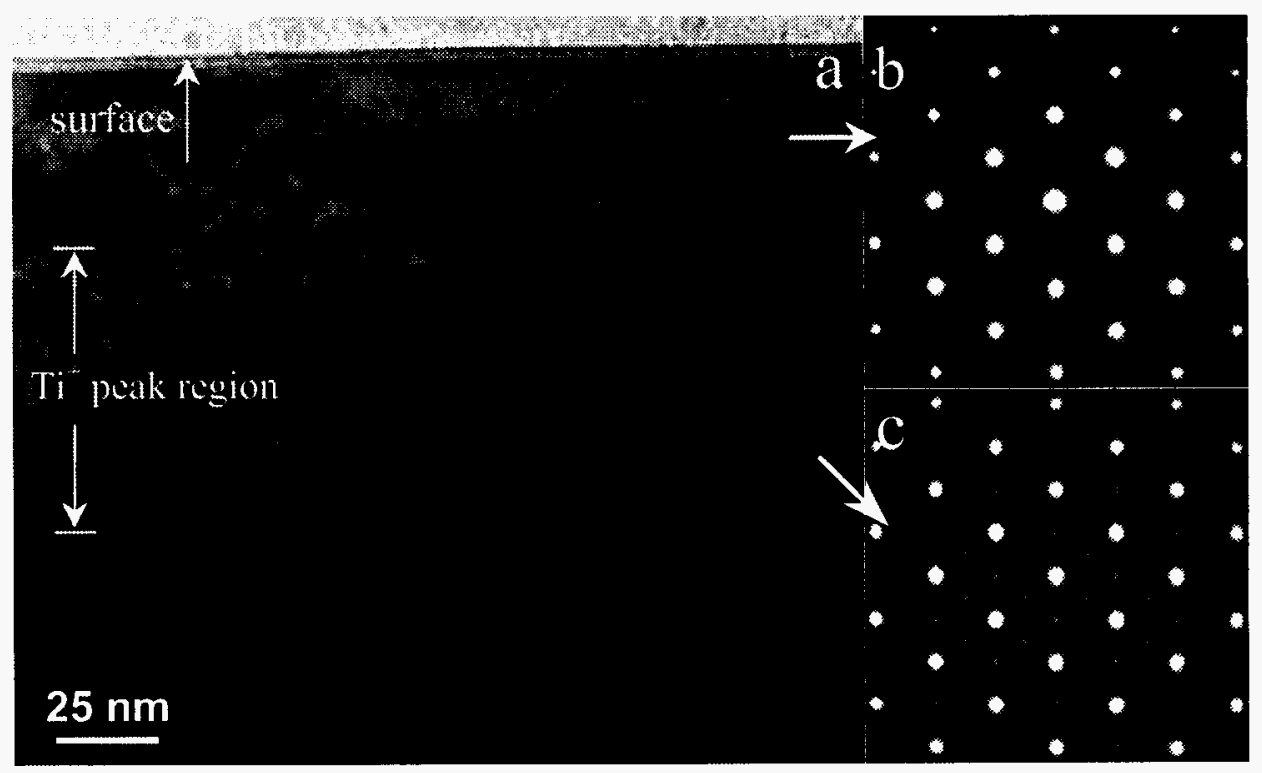

Fig. 5 (a) Bright-field cross-sectional TEM micrograph showing the depth dependent microstructure of YSZ after $180 \mathrm{keV}$ Ti-implantation to $1 \times 10^{17}$ ions $/ \mathrm{cm}^{2}$ at room temperature; (b) selected area electron diffraction (SAD) pattern of [110] zone from the surface area in showing YSZ structure; (c) SAD pattern of [110] from the implantation peak revealing superlattice spots corresponding to the cation ordering in the pyrochlore structure.

\subsection{Effects of Xe implantation in spinel-zirconia/ceria composites}

The spinel-YSZ composite is considered as a good candidate for inert fuel matrix based on the following considerations: (1) YSZ is isostructural (fluorite structure) with $\mathrm{UO}_{2}, \mathrm{PuO}_{2}, \mathrm{AmO}_{2}$ and $\mathrm{ThO}_{2}$, it has a high solubility for actinides and is considered to be an excellent actinide host phase. For example, $\mathrm{PuO}_{2}$ and $\mathrm{ZrO}_{2}$ form solid-solutions over the entire binary composition range above $1473 \mathrm{~K}$. (2) The relatively low thermal conductivity of YSZ is not desirable for its use as an inert fuel matrix. On the other hand, spinel has a higher thermal conductivity, but is not a good host for the actinides.

In our study, two spinel based composite specimens containing either $\left(\mathrm{Zr}_{0.85} \mathrm{Y}_{0.15}\right) \mathrm{O}_{2}$ or $\left(\mathrm{Zr}_{0.5} \mathrm{Ce}_{0.5}\right) \mathrm{O}_{2}$ particles were implanted with $200-400 \mathrm{keV}$ Xe ions at $873 \mathrm{~K}$ using the IVEM-Tandem Facility at Argonne National Laboratory. Ce is used as a simulant for Am, an element to be transmuted in the inert matrix fuel, as the two elements have similar chemical properties. In situ transmission electron microscopy (TEM) was conducted during the implantation in order to follow the evolution of the microstructure. At a fluence between $2.4 \times 10^{20}$ to $3 \times 10^{20}$ ions $\mathrm{m}^{-2}$ (up to $50 \mathrm{dpa}$ and 4.7 at \%), large Xe bubbles of $50-100 \mathrm{~nm}$ developed at the boundaries of the small oxide particles (Figs. 6 and 7), while a high density of dislocation loops (up to $8 \mathrm{~nm}$ in diameter) and much smaller bubbles (up to $\sim 4 \mathrm{~nm}$ in diameter) formed in the spinel matrix. No large bubbles were observed at the boundaries between the spinel grains. These results suggest that the boundaries between spinel and oxide particles are preferred sites for fission gas accumulation. 


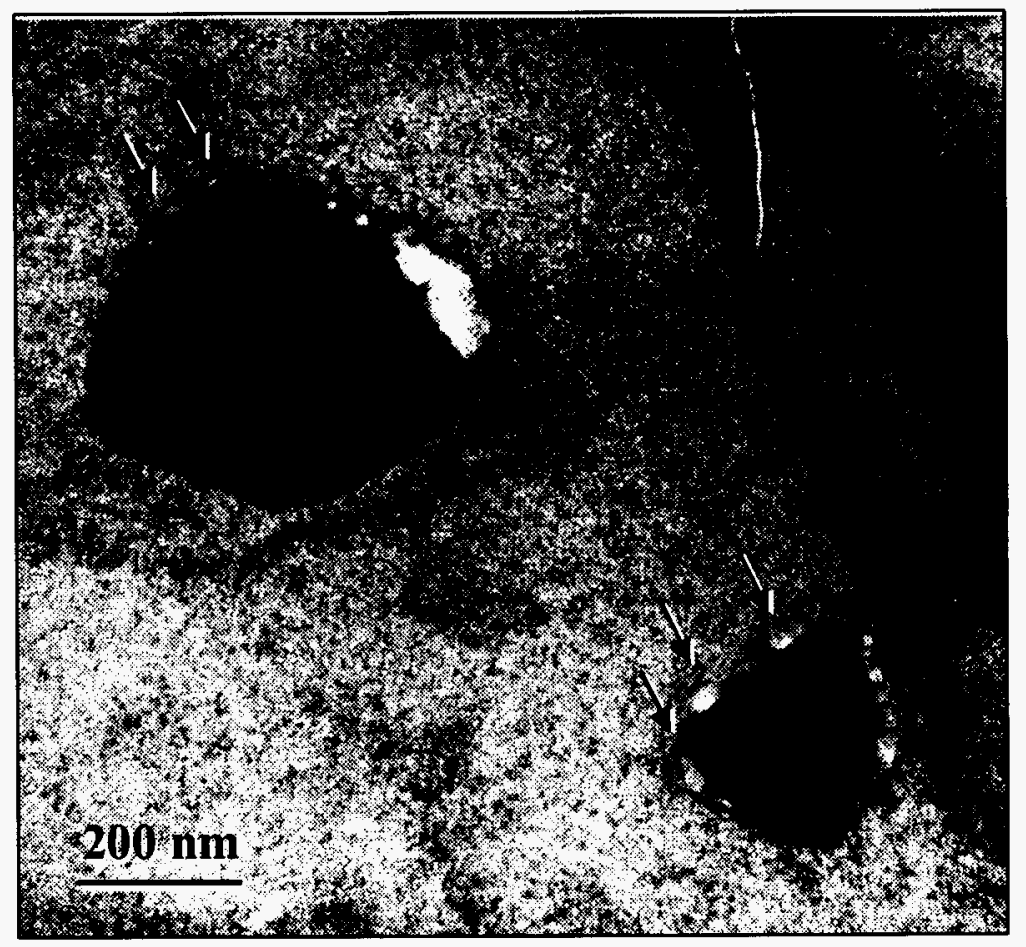

Fig. 6. TEM micrograph from a spinel- $\left(\mathrm{Zr}_{0.5} \mathrm{Ce}_{0.5}\right) \mathrm{O}_{2}$ composite after implantation with $200 \mathrm{keV}$ $\mathrm{Xe}^{+}$to $2 \times 10^{20}$ ions $\mathrm{m}^{-2}$ plus $400 \mathrm{keV} \mathrm{Xe} \mathrm{e}^{+}$to $3.75 \times 10^{19}$ ions $\mathrm{m}^{-2}$ at $873 \mathrm{~K}$ showing the formation of large $\mathrm{Xe}$ bubbles at the $\left(\mathrm{Zr}_{0.5} \mathrm{Ce}_{0.5}\right) \mathrm{O}_{2}$ particle boundaries.
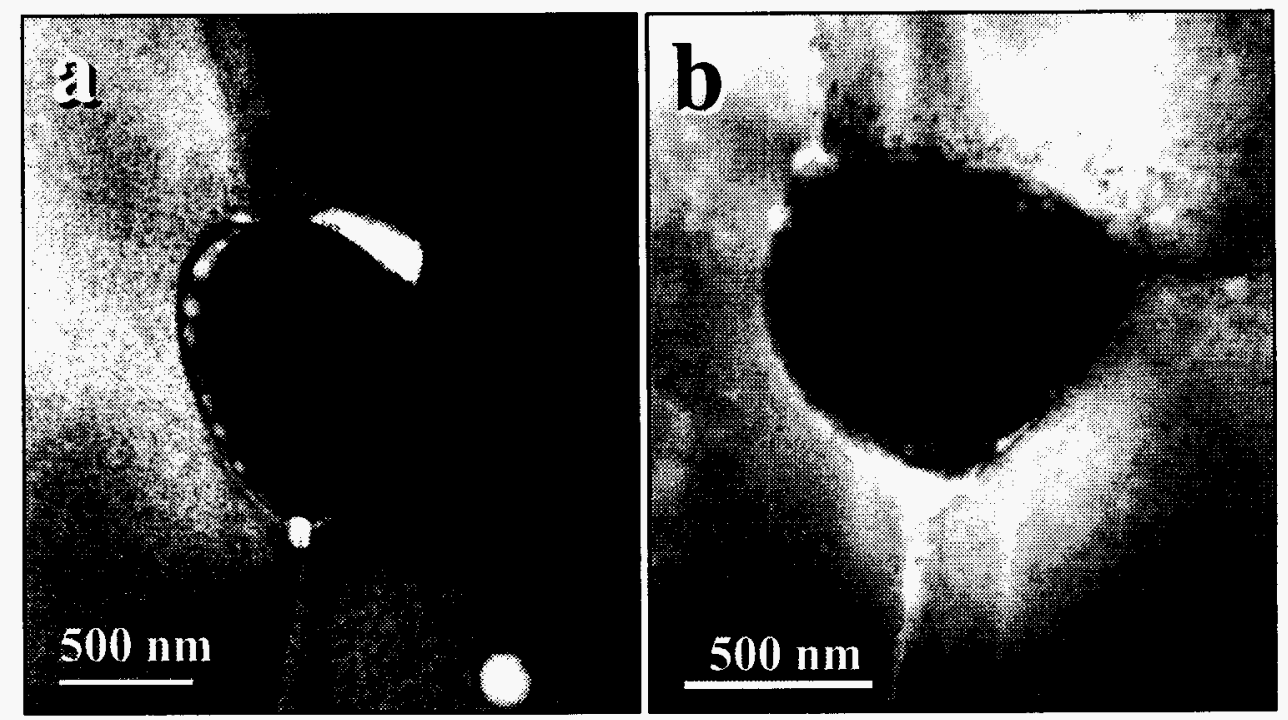

Fig. 7. TEM micrographs from a $400 \mathrm{keV} \mathrm{Xe}{ }^{+}$implanted spinel- $\left(\mathrm{Zr}_{0.85} \mathrm{Y}_{0.15}\right) \mathrm{O}_{2}$ composite after $3 \times 10^{20}$ ions $\mathrm{m}^{-2}$ at $873 \mathrm{~K}$ showing the formation of large Xe bubbles at the $\left(\mathrm{Zr}_{0.85} \mathrm{Y}_{0.15}\right) \mathrm{O}_{2}$ particle boundary. The bubbles on the YSZ particle in (b) are believed to be at the boundary above or below the particle. 


\subsection{Effects of temperature on the behavior of fission products in YSZ}

The temperature effects on the behavior of long-lived fission product, such as cesium, xenon and iodine, in YSZ based inert matrix fuel and waste form have been investigated through ion implantation and thermal annealing. Implantation of $400 \mathrm{keV} \mathrm{Cs}{ }^{+}$and 200 $\mathrm{keV} \mathrm{I}{ }^{+}$were conducted at room temperature with ion fluences up to $1 \times 10^{21}$ ions $/ \mathrm{m}^{2}$. Subsequent annealing was completed at $800^{\circ} \mathrm{C}$ and $1000^{\circ} \mathrm{C}$. Cross-sectional TEM was performed to reveal the depth-dependent microstructure. As previously reported, amorphization of YSZ occurred where $\mathrm{Cs}^{+}$concentration exceeds 8 at. \% (300 dpa) upon $\mathrm{Cs}^{+}$implantation. After annealing at $1000^{\circ} \mathrm{C}$, a high density of bubbles $\left(2 \times 10^{16}\right.$ bubbles $/ \mathrm{cm}^{3}$ ) with diameters from 6 to $60 \mathrm{~nm}$ formed while the amorphous band crystallized. No amorphization was observed upon $\mathrm{I}^{+}$implantation. $\mathrm{I}^{+}$bubbles formed after annealing and the bubble density reached $8 \times 10^{16} / \mathrm{cm}^{3}$ at $1000^{\circ} \mathrm{C}$. The diameters of bubbles ranged from 3 to $18 \mathrm{~nm}$. At higher annealing temperatures, the bubble size increased causing larger volume swelling. The distribution and migration of implanted ions in a spinel-YSZ composite material have also been studied. The most recent results on this topic have been presented at the 8th International Workshop on Inert Matrix Fuel held at Tokai, Japan.

\section{Summary and Future Work}

In this NEER program, we investigated the effects of radiation and fission product incorporation for the in-reactor performance of a variety of inert matrix fuels. The results of this research have been published in 14 research papers and been presented in 17 national or international conferences. The graduate student supported under this NEER grant has been trained not only at the University of Michigan, but also at Argonne National Laboratory to use a national facility for research. As the result of the support of this NEER grant, the student received two prestige awards at national conferences.

This work has lead us to realize that special application nuclear fuels can also find dual application as durable waste forms. The inert matrix fuel is designed to contain a balanced mixture of inert material, fissile nuclides and neutron absorbers that then controls the reactivity of the fuel. Such a strategy should also allow direct disposal of the used fuel as a waste form, without reprocessing after once-through burn-up. The development of inert-matrix fuels/waste forms is not only a part of the solution for the disposition of plutonium from dismantled nuclear weapons, but such fuels can be a necessary component of reprocessing strategies for commercial nuclear fuels.

We have been participating in an international research collaboration on inert matrix fuels (IMF) that was initiated at the Paul Scherrer Institute (Switzerland) in 1994. We have attended and presented research results at each annual workshop (most recently at Tokai, Japan, in October 2002), and future work is needed to extend this work to include the development of new nuclear waste forms (NNWF). 